\title{
Knowledge acquisition from foreign parents in international joint ventures: an empirical examination in the Hungarian context
}

\author{
Marjorie A Lyles ${ }^{1}$ and Jane $\mathrm{E}$ \\ Salk ${ }^{2}$ \\ ${ }^{1}$ Indiana University School of Business, \\ Indianapolis, IN, USA; ${ }^{2}$ Groupe ESSEC, \\ Department of Strategy and Management, \\ Cergy-Pontoise Cedex, France
}

Correspondence: MA Lyles, Indiana University School of Business, 801 West Michigan Street,

Indianapolis, Indiana 46202-5151, USA.

Tel: + 13172742558 ;

Fax: + 1317274 3312;

E-mail: mlyles@iupui.edu

\begin{abstract}
In this paper, we examine organizational characteristics, structural mechanisms and contextual factors that influence knowledge acquisition from the foreign parent in international joint ventures (IJVs). We in turn relate assessments of knowledge acquisition to IJV performance. The data come from a survey of IJVs in the Hungarian context, where learning and knowledge acquisition from the foreign parent is thought to be particularly critical. Adaptation mechanisms, such as capacity to learn, articulated goals, and structural mechanisms, such as the provision of training, technology and managerial assistance by foreign parents, all were positively associated with the degree to which IJVs reported acquiring knowledge from their foreign parents. We also found limited support for the belief that cultural conflicts can impede knowledge acquisition, but only for two-party joint ventures with 50/50 equity arrangements. We also looked at the relationship between knowledge acquisition and different dimensions for evaluating IJV performance. The relationship between knowledge acquisition and performance was significant for all indicators of performance, through knowledge acquisition from the foreign parent and the organizational characteristics hypothesized to enhance IJV knowledge acquisition affected assessments of some dimensions of performance more than others. Our findings contribute to advancing knowledge about the relationship between organizational characteristics and organizational knowledge acquisition in IJVs, as well as the relationships between knowledge acquisition and different dimensions of IJV performance.

Journal of International Business Studies (2007) 38, 3-18.

doi: 10.1 1057/palgrave.jibs.8400243
\end{abstract}

Keywords: international joint ventures; organizational knowledge acquisition; joint venture performance

\section{Introduction}

The strategic management and IJV literatures assert that learning, knowledge acquisition and adaptation are important rationales for the creation of international joint ventures, contributing significantly to IJV performance (Hamel, Doz and Prahalad, 1989; Hamel, 1991; Kogut and Zander, 1992; Lyles and Schwenk, 1992; Lyles and Baird, 1994) and to organizational performance more generally (Fiol and Lyles, 1985; Huber, 1991; Kogut and Zander, 1992; Nonaka, 1994). However, empirical research has yet to establish which structural mechanisms and IJV characteristics determine the degree to which an IJV can be said to have learned from its foreign parent, whether the same mechanisms and characteristics affect IJV performance, and the extent to which the construct of
Received: 1 September 1995

Revised: 1 February 1996

Accepted: 1 May 1996

Online publication date: 21 December 2006 
knowledge acquisition mediates these relationships. It is these gaps in the strategy and IJV literature that this empirical study seeks to fill.

This paper will begin by linking knowledge acquisition to theories of organizational learning, considering the specific context of knowledge acquisition from foreign parents by IJVs. We consider learning and knowledge acquisition to be closely linked and, therefore, we will use both literatures to derive a set of IJV characteristics and structural mechanisms hypothesized to enhance the acquisition of knowledge from the foreign parent. In conceptualizing the probable linkages between knowledge acquisition and performance, we argue that different categories of performance need to be distinguished and examined separately business performance, performance in terms of building the skills and competencies of IJV personnel, and overall performance in relation to effort and expected outcome of the IJV.

We will establish an association between measures of performance and knowledge acquisition, and will develop and test a model of the determinants of knowledge acquisition from foreign parents by IJVs. Finally, we will compare and contrast the degree to which the hypothesized relationships between IJV characteristics and knowledge acquisition, and between knowledge acquisition and performance, hold for IJV organizations assessed as High Knowledge-Acquirers $v s$ those assessed as Low Knowledge-Acquirers. We use data collected on IJVs based in Hungary, because in the transitional economies of Eastern Europe, foreign parents are seen as reservoirs of both technical know-how and managerial (process-related) knowledge (Child and Markoczy, 1993; Hisrich and Szirmai, 1993; Markoczy, 1993).

\section{Knowledge acquisition, performance and international joint ventures}

\section{Knowledge acquisition, learning and IJVs}

Knowledge is essentially related to human action (Nonaka and Takeuchi, 1995: 58). Individuals create knowledge, but organizations can create a context for individuals to create and amplify knowledge (Nonaka and Takeuchi, 1995: 59). The knowledge acquired from a foreign parent can be explicit or tacit, and can be grafted to take root into the IJV organization via socialization, internalization, and by combining different types of explicit knowledge to create new knowledge that is useful in the IJV context (Nonaka, 1994; Nonaka and Takeuchi, 1995).

Although Nonaka and Takeuchi (1995) assert that organizational learning is most closely related to internalization (in the case of IJVs, taking tacit knowledge from the parents and converting it into explicit knowledge), we believe that the organizational learning literature can be applied to suggest underlying organizational characteristics and structural mechanisms in cases of socialization (converting tacit knowledge from the parent into tacit IJV knowledge) and combination modes (combining types of explicit knowledge, which Nonaka and Takeuchi clearly related to training and educational programs by firms). They also suggest that explicit knowledge and tacit knowledge are not mutually exclusive (Nonaka and Takeuchi, 1995). Thus, explicit knowledge originating from a source organization such as a foreign parent might yield tacit knowledge in the IJV and vice versa.

The role of top managers is important for acquiring knowledge. Prahalad and Bettis (1986), Lyles and Schwenk (1992), and von Krogh et al. (1994) underscore that acquiring new knowledge results from organizational members sharing experiences and prior learning. Further, top management plays an important role in defining knowledge structures. The notion of a self-identity or core set of beliefs (Lyles and Schwenk, 1992; von Krogh et al., 1994) provides a legitimizing function for assessing new knowledge acquisition in the context of the existing knowledge structure. Hence, the top management, including IJV general managers, play an important role in defining the selfidentity and in building knowledge structures (Huber, 1991; von Krogh et al., 1994). This would be especially true in small to mid-sized organizations, and IJVs where decision-making is more centralized than in larger organizations, and where general managers take more active direct roles in business activities.

Knowledge acquisition can arise from the direct experience of the organization and its members (Fiol and Lyles, 1985; Huber, 1991; Lyles, 1988, 1994). Thus, 'history provides an important starting point for knowledge development' (von Krogh et al., 1994: 60). In young or new organizations or IJVs, knowledge structures are simple, and the parent firms become important for transferring knowledge in order to further knowledge development (Lyles and Schwenk, 1992).

Organizations and their members also acquire knowledge from others through 'grafting' indivi- 
duals with special expertise, such as using expatriates in IJVs and/or through 'vicarious learning' from other organizations (Huber, 1991; Westney, 1988). Learning through grafting of cognitive orientations to managerial and technical matters closely corresponds to Nonaka and Takeuchi's (1995) notions of socialization and internalization. Socialization can involve conscious or unconscious acquisition of culturally embedded knowledge via exposure to reference individuals, groups and organizations (in this case, the referents would be from the foreign parent). Internalization comes from developing experience over time with explicit knowledge from the parent that eventually becomes part of orientations and routines in the IJV itself.

In the case of Hungarian IJVs the foreign parent may be a vital source of both tacit and explicit knowledge. While transfers of technical know-how might occur relatively rapidly at the outset of an IJV, for Hungarian IJV managers and employees to absorb and adapt the administrative and managerial skills of their Western parents, it is likely to require the active involvement of managers from the foreign partner(s) so that local employees can develop a knowledge base from being exposed to ideas, concepts and processes over time (Nonaka, 1994). Active participation is also commonly associated with having parents with equal or nearly equal equity participation (Killing, 1983; Salk, 1992).

We, therefore, are concerned with the knowledge acquired from the foreign parent. This knowledge can take the form of tacit or explicit knowledge, or a combination of the two. For small or mid-sized organizations, general management plays an important role in framing and contributing to the organizational knowledge structure. Changes in the organizational knowledge structure occur as a result of the interpretation of new knowledge that is grafted from others, evaluated in light of the past history and routines of the organization, and/or treated as new and creative knowledge structures (Lyles and Schwenk, 1992).

\section{IJV factors affecting knowledge acquisition}

The model in Figure 1 identifies factors that may predict higher levels of knowledge acquisition from the foreign parent and, in turn, higher levels of performance. Figure 1 proposes that not only are certain IJV characteristics associated with knowledge acquisition, but that the degree of knowledge acquisition from the foreign parent, in turn, should be associated with better IJV performance.

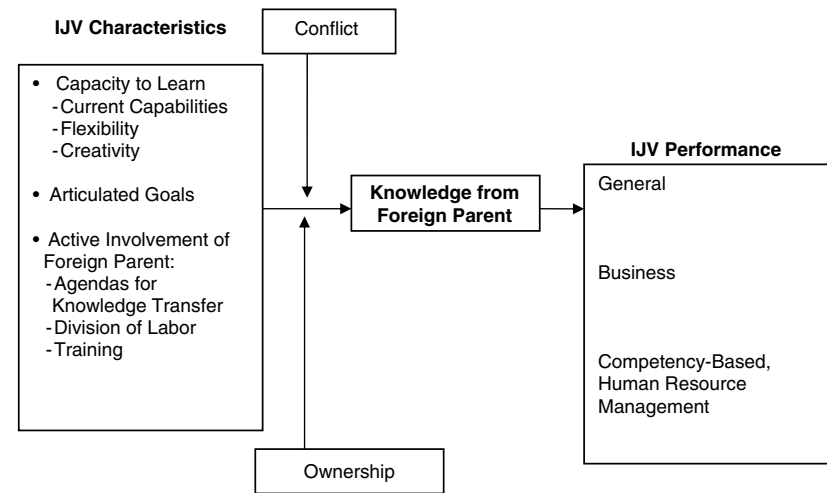

Figure 1 The knowledge acquisition-performance link.

Knowledge acquisition from the foreign parent is in the middle of Figure 1, because knowledge acquisition from the foreign parent is an ongoing activity rather than a discrete outcome, and because we examine whether the reported amount of knowledge acquisition from the foreign parent mediates the relationship between organizational features and various types of performance.

\section{IJV characteristics}

Based on the IJV and learning literatures, we propose several factors thought to affect the amount of knowledge acquisition by an IJV from its foreign parents. On the left-hand side of Figure 1 are three categories of mechanisms and IJV characteristics hypothesized to affect both knowledge acquisition from the foreign parent and IJV performance outcomes: capacity to learn, articulated goals and strategies and the active involvement of the foreign parent in the IJV. According to the organizational knowledge acquisition and IJV literatures reviewed above, each of these should be positively associated with ratings of the knowledge acquired from the foreign parent.

\section{Capacity to learn}

Some organizations have a greater capacity to absorb, circulate and utilize information than others (Cohen and Levinthal, 1990), thus absorptive capacity is an important factor in determining whether new knowledge is acquired. A flexible (non-bureaucratic, non-hierarchical) organizational structure and approach to management is thought to be associated with higher capacities for knowledge acquisition (Dodgson, 1993; Lyles and Baird, 1994). Organizational flexibility promotes absorptive capacity and the knowledge transfer process by encouraging greater receptivity of organization 
members to new stimuli from the outside, by promoting collaboration and exchanges of information within the organization and by granting members greater latitude in altering activity patterns and ways of doing things to adapt to perceived changing needs and conditions (Fiol and Lyles, 1985; Brown and Duguid, 1991; March, 1991; Hedlund, 1994). Hence, we hypothesize that:

Hypothesis 1: The greater the capacity to acquire and use information of the IJV organization, the greater the amount of knowledge acquisition from the foreign parent [CAPACITY]

\section{Articulated goals and milestones}

These can also facilitate knowledge acquisition (Hill and Hellriegel, 1994; Nonaka and Takeuchi, 1995). First, articulated goals advance knowledge acquisition by focusing members upon the same vision or mission (von Krogh et al., 1994). Second, articulated goals and plans provide a common measure against which to access and adjust individual and collective actions and their outcomes, while at the same time allowing IJVs the freedom and flexibility to create their own implementation plans and subgoals. Finally, they provide mechanisms for evaluating (1) the state of collective understanding and the efficacy of action; (2) the discrepancies between explicit goals and plans; (3) the progress assessed at a particular time; and (4) the new knowledge needed to correct deficiencies or difficulties. Likewise, different types of articulated strategies might have different implications of the amount and type of knowledge transfer into the IJV. Having an explicit, written framing for IJV organizational goals and plans should selectively focus IJV employees on acquiring potentially useful knowledge from the foreign parent. Therefore:

Hypothesis 2: IJVs with articulated goals will report more knowledge acquisition from the foreign parent than those IJVs that have not developed such written documents [GOALS].

\section{Active involvement}

Information and experience might be rich with potential knowledge, but individuals and groups need information such as signals or other cues, to draw their attention toward potential knowledge. The explicit framing of contributions from a foreign parent for an IJV is one mechanism for identifying potentially useful knowledge to be acquired and adapted within the IJV. The socialized and internalized knowledge from the parent firms can provide an important basis for future knowledge development (Markoczy, 1993). Particularly in the East European/Hungarian context, foreign parents often provide technology, and are also viewed as possessing administrative and management know-how that has been sorely lacking in managers and organizations in Eastern Europe (Child and Markoczy, 1993).

Hypothesis 3a: The degree to which there is active involvement of the foreign parent through ex ante division of labor between the parents should be associated with higher levels of reported knowledge acquisition [CONTRIBUTE].

Hypothesis 3b: The degree to which the explicit contribution of a foreign parent has been identified as technical know-how should be positively associated with the degree to which an IJV has acquired knowledge from its foreign parents [TECHCNTRIBUTE].

Hypothesis 3c: The degree to which the explicit contribution of a foreign parent has been identified as managerial know-how should be positively associated with the degree to which an IJV has acquired knowledge from its foreign parents [MGRCNTRIBUTE].

The training of local employees by a foreign parent can be seen as a vehicle for transmitting informational content (explicit knowledge) and socially embedded information (Nonaka, 1994). As conduits for embedded knowledge, training programs can be important vehicles for establishing contact between local employees and parent employees. Thus:

Hypothesis 4: The degree to which the explicit contribution of a foreign parent has been identified as being responsible for the training of the local workforce should be positively associated with the degree to which an IJV has acquired knowledge from its foreign parents [TRAINING].

\section{Conflict and misunderstandings}

The IJV literature identifies two further factors believed to affect the acquisition of a parent's knowledge. The first of these is differences and conflict between the parents. Conflict between the parents can be indicative of disagreement concerning goals and/or operational or managerial 
expectations. As such, parental conflicts can impede the flow of information between the parents and the IJV, and can send negative or conflicting signals to IJV employees about using the foreign parent as a knowledge reference. A theme that runs through much of the literature on IJVs is that conflict in general, and cultural conflicts in particular, can lead to instability and poor performance (Bivens and Lovell, 1966; Killing, 1983; Lane and Beamish, 1990). Conflict and cultural misunderstandings can minimize flows of information and learning (Fiol and Lyles, 1985; Lane and Beamish, 1990; Parkhe, 1993; Salk, 1992). Though misunderstandings arising due to cultural differences need not accelerate conflict if managers in an IJV are adequately prepared, it is the case that foreign companies from some countries may tend to be more attuned to what it takes to manage successfully in Hungary. We look both at cultural conflict and parent-related conflicts to test the following:

Hypothesis 5: The greater the degree of reported cultural and other sources of conflict for an IJV, the lower the reported levels of knowledge acquisition [CULTURE/PARCONFLICT].

\section{Ownership type}

This is a second factor identified by the IJV literature as potentially affecting knowledge acquisition by the IJV. Killing (1983) distinguishes between dominant partner and shared management IJVs, suggesting that the latter ought to have greater difficulties than the former. Moreover, Killing suggests that 50/50 IJVs, because no one parent has dominant control, are more likely to have difficulties when cultural differences are present. Some recent case studies of shared management IJVs suggest that a 50/50 sharing of equity (which may or might not be accompanied by equal say over day-to-day managerial affairs) is selected in order to mobilize the commitment and skills of both partners. The shared management IJVs studied by Salk (1992) were found to have a strong strategic rationale of transferring knowledge and skills of both partners into the IJV.

Ownership structure might moderate the effects of cultural conflict (CULTURE), other parent-related conflicts (PARCONFLICT), and articulated goals (GOALS) (Harrigan, 1986; Geringer and Hebert, 1989; Salk, 1992). Specifically, shared management $(50 / 50)$ IJVs have often been characterized by researchers as particularly sensitive to cultural differences and parental tensions (Killing, 1983;
Salk, 1992, 1996). We expect higher levels of knowledge acquisition in shared management IJVs where the spread of information and tacit knowledge is less risky (Salk, 1992). Hence, we test the following:

Hypothesis 6a: IJV ownership type moderates the association between reported levels of knowledge acquisition and the following variables: cultural conflicts and misunderstandings, parental sources of conflict, and articulated goals. $[O W N(D 1) ; O W N(D 2)]$

Hypothesis 6b: There will be higher levels of knowledge acquisition in 50/50 two-partner IJVs than in IJVs with other forms of ownership.

\section{Knowledge acquisition and performance in IJVs}

From a resource-based perspective, knowledge transferred from the parent firms can be utilized to create and augment the competitive capabilities of the IJV. Although researchers have often discussed the importance of knowledge acquisition between the parent firms (Kogut and Zander, 1992; Szulanski, 1993), such transfer would be done occasionally through the conduit of the IJV. Hence, leveraging the knowledge, capabilities, and skills of the foreign parent, especially when the foreign parent comes from a sophisticated competitive and country context (Porter, 1986), can enhance the competitive advantage and performance of an IJV. That said, however, two methodological questions arise immediately. The first is how to define performance. The second question is whether a perceptual rating of the amount learned by an IJV can fully capture the associations between the factors proposed to enhance knowledge acquisition and the IJV's performance.

The performance of organizations, including IJVs, can be viewed in a variety of ways. Performance can be viewed in terms of meeting or exceeding financial or market objectives. Hence a variety of studies have looked at market share, profitability and ROI and/or assessments of these by top management. Such measures are problematic, however, in that it is difficult to make meaningful comparisons across IJVs that rule out differences in products, markets served, etc. (Geringer and Hebert, 1989; Parkhe, 1993; Hill and Hellriegel, 1994). Moreover, as the field of strategy has shifted toward viewing core competencies and embedded processes as sources of competitive advantage, it becomes desirable also to view performance in 
terms of the accumulated competencies acquired by organization members (Kogut and Zander, 1992; Hamel, Doz, and Prahalad, 1989). Viewing performance in terms of accumulated competencies may prove to be more closely linked (at least over the short-to-intermediate run) with knowledge acquisition than business performance. Finally, since IJV stability is subject to global feelings of trust and satisfaction on the part of the parties involved, it is desirable to look at the level of satisfaction of the IJV stakeholders, including the parent and IJV top management.

We therefore identify and analyze three distinct types of performance (Hill and Hellriegel, 1994). Performance can be viewed in terms of economic and business criteria (Harrigan, 1986), in terms of the accumulation of know-how and capabilities within the IJV (Kogut, 1988), and in terms of the overall performance in relation to effort and expected outcomes (Geringer and Hebert, 1991). Business performance includes measures such as business volume growth, achieving planned goals, making profits, achieving acceptable levels of employee productivity, lowering unit costs, and lowering overhead costs. Firms do not always enter into IJVs exclusively for, or primarily for, potential business performance of the JV as a stand-alone entity (Yan and Gray, 1994). Thus, another criterion for performance can be the degree to which the IJV builds competencies by developing its workforce, accumulating management skills, and creating the organizational capabilities for strategy implementation. Human resource performance is an important mechanism and measure of the adaptive or competency-building capabilities of the IJV organization (Brown and Duguid, 1991; Lyles 1988; Szulanski, 1993).

Hypothesis 7: Performance in terms of competency-based/human-resource development will be more strongly associated with levels of knowledge acquisition reported in the IJVs than assessments of business-related and general performance [HRPERF, BUSPERF, GENPERF].

\section{High vs Low Knowledge Acquirers}

While the regression models can capture average or mean relationships, it is also important to examine and understand variations in associations among variables for exceptionally low and exceptionally high knowledge-acquiring IJVs. We do that by utilizing the measure of knowledge acquisition given to us by the IJV general manager to identify high (upper standard deviation away from the mean) vs low (bottom standard deviation away from the mean) knowledge-acquiring subgroups. We then look at how they differ. We would expect:

Hypothesis 8: In higher knowledge acquisition IJVs, managers will report higher levels of the capacity to learn, articulated goals, and active involvement of the foreign parent, than will managers of lower knowledge acquisition joint ventures.

Having expatriate managers from the foreign parent working in the IJV can be an important conduit for knowledge transfer to local IJV management (Hamel, 1991; Kogut and Zander, 1992; von Hippel, 1988). Organizations are social communities in which individuals interact in an organizational and inter-organizational context (Brown and Duguid, 1991). Long-term relationships allow a social context to develop in which expertise can be communicated and shared. Expatriates serving as IJV managers are one mechanism through which a context for trust and sharing of information can evolve over time (Hedlund, 1994). Therefore:

Hypothesis 9: The IJVs that have higher levels of knowledge acquisition will tend to use more foreign-parent expatriates than will IJVs that report lower levels of knowledge acquisition.

\section{Methods}

\section{Sample selection}

A joint venture is a separate firm owned by two or more parent companies; thus, no wholly owned subsidiaries of foreign firms were included in the analysis. The stratified sample comprises a representative sample of small/medium joint ventures in Hungary, in terms of industries and the country-oforigin of the foreign partners. The sample and sampling technique were developed with the help of a Hungarian government agency that received information about the IJVs from the government. Sample stratification was based upon statistics provided by Hungary's Central Statistical Office, which show the percentage of firms in each industry and the percent from each country-oforigin of the foreign partners. The firms that participated were identified through directories, contacts, and the Hungarian government database. We were also able to control for JV size, age and type. The type and extent of the information 
collected in this project is unavailable elsewhere, since small IJVs do not have stringent reporting requirements in Hungary. Thus, the survey created a unique database for Hungary on small to midsized IJVs. Funding for the project was provided by two organizations interested in assessing the performance of mid-sized IJVs in Hungary, and a separate report was generated for these agencies.

The sample consists of a total of $201 \mathrm{small} / \mathrm{med}-$ ium sized IJVs with an average employee size of 72 employees. The majority of the IJVS were in manufacturing of machinery, electronics, textiles and food processing. The informants were the presidents or general managers of the IJVs. On average, they had already been in their current position for 3.4 years. Joint venture status was first verified over the telephone, and then a letter was sent to the IJV general manager requesting that he/ she participate in the study. The response rate was close to $25 \%$. It is possible that the sample is somewhat biased in the direction of better performing IJVs. We suspect that the worst-performing IJVs might be less likely to agree to an interview. Usually the main reason given by managers who did not agree to participate was that they were too busy.

Management of the project involved cooperation between the first author, a leading economic research institute in Hungary (Kopint-Datorg), and a group of carefully selected and trained Hungarian interviewers. In brief, the design of a structured interview resulted in the accumulation of data for each firm which detailed its founding, its management, its ownership structure, its financial management, and its competitive strategy. The authors trained the interviewers, pretested the survey instruments, and developed detailed instructions for the project manager at the research institute. The surveys were translated and backtranslated to avoid any language misunderstandings and the surveys were available in either Hungarian or English. The interviewers were bilingual and thus could conduct the interviews in the language most comfortable to the IJV manager. However, almost all the interviews were done in Hungarian.

This study extends other studies of IJVs in Hungary. Webster (1992) analyzed small manufacturing firms in Hungary in 1991 for a World Bank Study. Hamar (1993) provides an up-to-date review of IJVs based on data from the Central Statistical Office for the Joint Hungarian-International Blue Ribbon Commission Project on Foreign Direct Investment in Hungary. The current study builds on both of these reports by providing a more current and extensive database.

\section{Variables}

The definitions of the variables used to test our propositions are given in the Appendix. For those measures comprising scales constructed from multiple questionnaire items, consistency was assessed using Cronbach's alpha. In the case of human resource and business performance, confirmatory factor analysis with varimax rotation supported the appropriateness of creating these two scales out of a list of performance items evaluated by respondents. Scales included had a reliability of at least 0.7, (Nunnally, 1967) with one exception, which was the scale for competencies/human resource performance (HRPERF). The appropriateness of this HRPERF scale was supported by confirmatory factor analysis of a large array of performance-related questionnaire items, in addition to the Cronbach alpha level of 0.66 . In the case of our knowledge acquisition scale, confirmatory factor analysis also supported the assignment of items to this scale.

The operationalization of constructs is as follows (the Appendix provides more detail).

\section{Knowledge acquisition}

This scale was designed to assess knowledge acquisition from the foreign parent across a variety of areas, including product development and knowledge about foreign cultures. A seven-item scale $(K N O W L)$ summarizing Likert-type responses to the question, To what extent have you learned from your foreign parent (a) new technological expertise, (b) new marketing expertise, (c) product development, (d) knowledge about foreign cultures and tastes, (e) managerial techniques and (f) manufacturing processes (where $1=$ little; $5=$ to a great extent; alpha $=0.88$ ).

\section{IJV characteristics}

Nine variables operationalize IJV characteristics and knowledge acquisition mechanisms of interest. These include: CAPACITY (degree to which the IJV has the capacity to learn, as measured by a threeitem scale of Likert-type items, based on the extent to which the IJV is flexible and adapting to change, creative, and whether superiors know about employee performance; alpha $=0.71$ ); GOALS (indicates whether the IJV has written objectives and/or a written long-term plan (where $0=$ neither are written, $1=$ either are written, and $2=$ both are written); MGRCNTRIBUTE (a six-item scale that 
summarizes the degree to which the foreign parent(s) contributes to the IJV in the following areas: sales/marketing support, managerial resources, administrative support, emotional support, and time; alpha=0.84); TECHCNTRIBUTE (a three-item scale that summarizes the degree to which the foreign parent(s) contributes to the IJV in the following areas: product-related technology, manufacturing-related technology, and manufacturing support; alpha $=0.86$ ); CONTRIBUTE (extent to which the explicit division of labor was seen as having the foreign parent provide the technology while the domestic parent provides the manufacturing capability). Based on past work in Eastern European IJVs, this sort of division of labor is thought to be very common; TRAINING (the extent to which the foreign parent provides education and training of domestic managers); CULTURE (a twoitem scale that summarizes the extent to which cultural misunderstandings and cultural differences have been issues in the IJV organization; alpha $=0.87$ ); and PARCONFLICT (a three-item scale that summarizes the extent to which mistrust, conflict over the original IJV agreement, and cultural differences between the parents have been issues in the IJV; alpha $=0.79$ ).

We categorized the IJVs, based on the number of parents and equity shares into three types, following Killing (1983), and created two dummy variables for ownership type: $O W N$ (D1) (a dummy variable indicating whether the IJV was a 50/50 shared management IJV or not), and OWN (D2) (a dummy variable indicating whether the IJV had a dominant parent with a dominant equity share (of greater than 50\%). Multi-parent IJVs with no single dominant parent were coded as zero for both $O W N(D 1)$ and $O W N(D 2)$.

\section{Performance}

Past research shows a positive relationship between 'objective' and perceptual measures of firm performance (Dess and Robinson, 1984; Geringer and Hebert, 1989, 1991; Hansen and Wernerfelt, 1989). Thus performance was measured by asking the respondents to rate the IJV's performance on a scale of (1) poor to (5) excellent for items representing three dimensions of performance: business measures, competencies/human resources, and a general evaluation.

To test the external validity of these self-reported measures of performance from the IJV general managers, a subsample of foreign parent firms were asked to evaluate their IJV's performance using this same scale. There were high correlations between the IJV general manager's assessment and the assessment of the foreign parent of the IJV's performance, and there were no significant differences between the means.

We constructed three performance scales based on Likert-type items BUSPERF (a four-item Likerttype scale that summarizes the IJV's performance in the following areas: increasing business volume, increasing market share, achieving planned goals, and making profits; alpha=0.82); HRPERF (a twoitem Likert-type scale that summarizes the IJV's human resource competency-based performance in providing adequate worker training and improving management skills; alpha $=0.66$ ); and GENPERF (a three-item Likert-type scale that summarizes how the Hungarian parent, the foreign parent, and the respondent evaluate the IJV's performance; alpha=0.88).

\section{Data analysis}

We used SAS (version 6.03) to perform all of the data analyses and multiple regression (Pedhazur, $1982)$ to test our propositions. The analysis proceeded in two stages. In the first stage, we regressed IJV characteristics on reported levels of knowledge acquisition from the foreign parent, to test Hypotheses 1-6a. Analysis of variance was used to test $6 \mathrm{~b}$. We then tested Hypothesis 7 and looked more generally at associations between knowledge acquisition and the three performance indicators. The distribution of the firms on knowledge acquisition was used to determine the standard deviation and firms were categorized as High KnowledgeAcquirers or Low Knowledge-Acquirers. Those IJVs that scored above one standard deviation from the mean were categorized as High KnowledgeAcquirers and those who scored one standard deviation or more below the mean were categorized as Low Knowledge-Acquirers. T-tests were used to test for differences between High KnowledgeAcquirers and Low Knowledge-Acquirers.

Table 1 summarizes the zero-order correlations among the explanatory variables. We include KNOWL because we looked at this variable as a predictor of performance and a mediator of other relationships in the second stage of the analysis. Of intercorrelations within categories of explanatory variables, only two exceeded 0.50 (MGRCNTRIBUTE with TECHCNTRIBUTE and CULTURE with PARCONFLICT). Despite some intercorrelations, the effect sizes and patterns of significance generally remained robust and quite stable across models. 


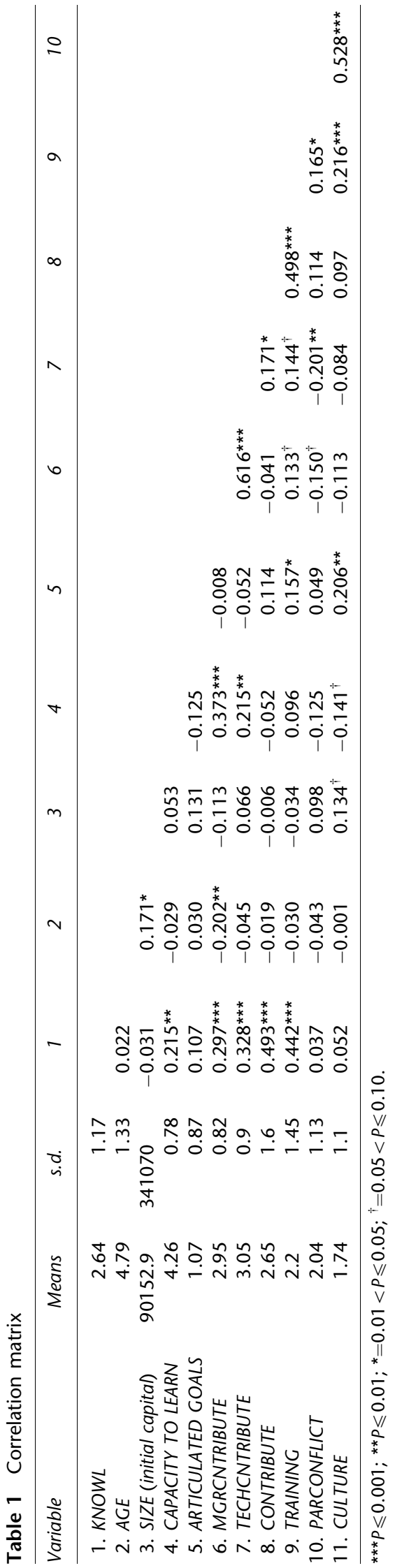

\section{Results}

\section{Results of the first stage of analysis}

Table 2 presents results for our multiple regression analysis looking at which IJV characteristics are associated with levels of knowledge acquisition from the foreign parent (KNOWL). Models 1-3 look at the effects of different categories of explanatory variables separately. Model 4, the full model, includes interaction terms (OWN (D1) or OWN (D2) X CULTURE and OWN (D1) or OWN (D2) X $G O A L S)$ to incorporate the ownership type as a significant moderator of the effects of culture conflicts and written goals on levels of knowledge acquisition from the foreign parent.

Our analyses generally support our hypotheses. Beginning with Model 1 of Table 2, which looks only at the effects of capacity to learn and written goals, we found support for hypothesis 1 and hypothesis 2 , where we predicted that both should be positively associated with knowledge acquisition levels. Model 1 achieved overall significance $(P \leq 0.01)$.

Model 2, which looked at mechanisms for the transfer of knowledge by the foreign parent, explained significantly more variance (adj. $R^{2}=$ $0.374 v s$ an adj. $R^{2}=0.054$ for Model 1 ). All of the

Table 2 Multiple regression analysis for KNOWL

\begin{tabular}{lcccc}
\hline & Model 1 & Model 2 & Model 3 & Model 4 \\
\hline AGE & -0.080 & 0.098 & -0.082 & 0.078 \\
SIZE & -0.006 & -0.014 & -0.011 & -0.042 \\
CAPACITY & $0.236^{* *}$ & & & $0.134^{\dagger}$ \\
GOALS & $0.149^{*}$ & & & 0.074 \\
MGRCNTRIBUTE & & $0.253^{* *}$ & & $0.257^{* *}$ \\
TECHCNTRIBUTE & & 0.074 & & 0.108 \\
TRAINING & & $0.219^{\star *}$ & & $0.160^{*}$ \\
CONTRIBUTE & $0.390^{\star * *}$ & & $0.350^{* * *}$ \\
CULTURE & & & 0.045 & 0.157 \\
PARCONFLICT & & & 0.002 & 0.053 \\
OWN (D1) & & & & 0.154 \\
OWN (D2) & & & & $0.263^{\dagger}$ \\
OWN (D1)X CULTURE & & & & $-0.362^{* *}$ \\
OWN (D2)X CULTURE & & & & 0.124 \\
OWN (D1)X GOALS & & & & $0.255^{*}$ \\
OWN (D2)X GOALS & & & & 0.149 \\
Adjusted R & & & & \\
F & 0.054 & 0.374 & 0.009 & 0.413 \\
Prob & 3.4 & 16.353 & 0.387 & 7.677 \\
N & 0.011 & 0.001 & 0.818 & 0.001 \\
\hline
\end{tabular}

${ }^{* * *} P \leqslant 0.001 ;{ }^{* *}=0.001<P \leqslant 0.01 ;{ }^{*}=0.01<P \leqslant 0.05 ;{ }^{\dagger}=0.05<P \leqslant 0.10$. a Ownership dummy variable: $O W N(D 1)=1$ for shared management in two parent JV, otherwise 0 ; OWN $(D 2)=1$ for dominant parent with majority equity share in two-parent JV, otherwise 0. 
effects with the exception of TECHCNTRIBUTE were strongly significant in the expected direction, lending support to hypotheses 3a, 3c, and 4. Model 3 tested hypothesis 5 and showed no support for a main effect of cultural conflicts and parent tensions and disagreements on reported KNOWL.

Another intermediate model estimated the main effects of all of the explanatory variables used in Models 1-3 taken together. In that model, GOALS, TECHCNTRIBUTE, CULTURE and PARCONFLICT were not significant (all others remained significant with effect sizes similar to those in the other models). We then used dummy variables for ownership (OWN D1 and OWN D2) and tested for moderation (hypothesis 6a), using criteria laid out by Baron and Kenny (1986). Testing for moderation revealed that ownership did fulfill all of the criteria for moderation for CULTURE and GOALS, though this was only significant for 50/50 shared management IJVs.

Model 4 presents results from estimation of our full model, including ownership as a moderator of CULTURE and GOALS. Capacity, managerial contributions, training by the foreign parent and the division of labor all continued to be significant, with effects in the proposed directions. What the interaction terms indicate is that cultural conflicts and goals indeed were associated with levels of reported knowledge acquisition, but only for the shared management type of IJV (OWN $(D 1)=1)$. For shared management joint ventures only, the effects of cultural conflicts and articulated goals and plans were significant in the directions predicted by hypotheses 2 and 5 . Model 4 explained roughly $41 \%$ of the variance of the dependent variable, though the incremental increase in variance explained over Model 2 was not significant.

Table 3 shows the results of the ANOVA used to test hypothesis $6 \mathrm{~b}$. It shows significant differences in the levels of reported knowledge acquisition in the three ownership categories of the IJVs. Twoparent 50/50 shared ownership IJVs report the highest level of knowledge acquisition while IJVs with three or more parents report the least amount of knowledge acquisition. Hypothesis $6 \mathrm{~b}$ was supported.

\section{Results from stage two of the analysis}

We took the analysis a further step by looking at the association between KNOWL and three separate indicators of performance. KNOWL failed to function as a mediator variable for any of the
Table 3 ANOVA of knowledge acquisition by ownership categories

\begin{tabular}{lccccc}
\hline & $\mathrm{N}$ & Mean & s.d. & F-ratio & Probability \\
\hline Two-parent (50/50) & 21 & 3.17 & 1.09 & 3.53 & 0.03 \\
Two-parent Dominant & 86 & 2.73 & 1.16 & & \\
Three+parent IJVs & 84 & 2.45 & 1.23 & & \\
\hline
\end{tabular}

performance types. Intermediate models suggested that CULTURE and CONTRIBUTE added little to the analyses involving performance, and looking at ownership as a moderator for CULTURE did not change this result. Moreover, past research and theory provided no a priori rationale for positing ownership type as a moderator for CONTRIBUTE. Hence, we examined univariate models with KNOWL and models with IJV characteristics (eliminating CULTURE, CONTRIBUTE, and OWN).

Table 4 compares the results for a model with KNOWL alone (Model 1 for each type of performance) with results for a full model without KNOWL. Hypothesis 7, which suggests that KNOWL should be a better predictor for the Human Resource-related performance than for the other two types, was generally supported by comparing both Models 1 and 2 for HR/Competence-related performance to those same models regressed on the other two types of performance. KNOWL by itself had a larger coefficient for HRPERF than for GENPERF (0.259 vs 0.121). The coefficient for BUSPERF was 0.148, also supporting hypothesis 7 . Moreover, KNOWL for HRPERF explained more than $6 \%$ of the variance, compared with less than $1 \%$ for GENPERF and 2\% for BUSPERF. Comparing across the full models (Model 2 of each pair), the variables in this model explained $30 \%$ of the variance in assessments of HR-related performance and $28.6 \%$ of the variance in general assessments of performance, compared with only $16.9 \%$ of business/economic performance. Thus, the full model provides some support for hypothesis 7 . The adjusted $R^{2}$ for HRPERF and GENPERF are close in size and are far more robust than for BUSPERF.

Because the main goal of this second stage analysis was to test Hypothesis 7 and to examine whether KNOWL mediated relationships between organizational characteristics and performance, we made no a priori predictions of how patterns of significance for individual organizational factors would differ for different types of performance. However, some of these results are also interesting. CAPACITY was the only indicator that was a strong 
Table 4 Multiple regression analysis for performance

\begin{tabular}{|c|c|c|c|c|c|c|}
\hline \multirow[t]{2}{*}{ Models $^{\mathrm{a}}$} & \multicolumn{2}{|c|}{ General performance } & \multicolumn{2}{|c|}{ Business performance } & \multicolumn{2}{|c|}{ Human resource performance } \\
\hline & 1 & 2 & 1 & 2 & 1 & 2 \\
\hline$A G E$ & & $0.142^{*}$ & & 0.090 & & -0.057 \\
\hline SIZE & & -0.056 & & -0.006 & & -0.017 \\
\hline KNOWL & $0.121^{\dagger}$ & & $0.148^{*}$ & & $0.259 * * *$ & \\
\hline CAPACITY & & $0.265^{* * *}$ & & $0.312^{* * *}$ & & $0.378^{* * *}$ \\
\hline GOALS & & 0.081 & & $0.145^{*}$ & & $0.246^{* * *}$ \\
\hline MGRCNTRIBUTE & & $0.256^{\star *}$ & & 0.075 & & $0.157^{\dagger}$ \\
\hline TECHCNTRIBUTE & & 0.065 & & 0.139 & & 0.104 \\
\hline TRAINING & & $-0.117^{\dagger}$ & & 0.022 & & 0.045 \\
\hline PARCONFLICT & & $-0.208^{\star \star}$ & & -0.101 & & $-0.115^{\dagger}$ \\
\hline Adjusted $R^{2}$ & 0.009 & 0.286 & 0.017 & 0.169 & 0.062 & 0.300 \\
\hline$F$ & 2.803 & 9.144 & 4.256 & 5.148 & 13.550 & 9.742 \\
\hline Prob & 0.096 & 0.001 & 0.041 & 0.001 & 0.001 & 0.001 \\
\hline$N$ & 191 & 164 & 191 & 164 & 191 & 164 \\
\hline
\end{tabular}

${ }^{a}$ Model $1=$ univariate with $K N O W L ;$ Model $2=$ main effects of influencing variables. All coefficients are standardized. ${ }^{* * *} P<0.001 ;{ }^{* *} 0.001<P<0.01 ;{ }^{*} 0.01<P<0.05 ;{ }^{\dagger} 0.05<P<0.10$.

predictor of performance for all three performance measures. This suggests that organizational flexibility and creativity have far-reaching ramifications for IJV performance. Articulated goals and business plans (GOALS) was a highly significant predictor of $H R P E R F$, and was the only variable besides organizational capacity to be significantly associated with BUSPERF.

Conflict between the parents only was a significant predictor of the general assessment of IJV performance, and the negative coefficient $(P \leqslant 0.01)$ suggests that higher levels of parent conflict are associated with lower ratings of general IJV performance. The same variable also had a marginally significant effect on HR-related performance. This is not surprising, given that general assessments of IJV performance are thought to be affected by feelings of trust. It may be that parent conflicts result in less energy being devoted to developing IJV personnel and that this low investment level also affects assessments of general performance as well as HR-related performance.

\section{Results of comparison of high vs low knowledge acquirer joint ventures}

Our purpose in looking at the differences between High $v s$ Low Knowledge-Acquirers was to determine if there were differences between the groups that would indicate the presence of greater competencies for knowledge transfer in the High Knowledge-Acquirers. Table 5 compares high and low knowledge-acquiring IJVs. There were no signifi- cant differences between the groups for age, size, type of firm, or number of foreign parents. High Knowledge-Acquirers seem to have a greater capacity to learn, articulated goals, and active involvement of the parent in making managerial and technical contributions (hypothesis 8). Cohen and Levinthal (1990) suggested that we might expect the High Knowledge-Acquirers to demonstrate prior relevant experiences that would facilitate knowledge transfer, but we found no differences between the groups in terms of characteristics or backgrounds of the top management. Since both groups of IJVs are young, there would not be a strong history of prior relevant experiences. However, the Higher Knowledge-Acquirers have significantly more employees from the foreign parent working in the IJV, which helps to create the opportunity for interactions and a basis for knowledge transfer (hypothesis 9). The High Knowledge-Acquirers also performed better in Business Performance and in Human Resource (Competency-based) Performance. There were no significant differences between the groups in the conflict measures. Both categories show that the mean number of parents was about 2.8. Although there were no significant differences between the groups in terms of number of parent firms, this variable needs more exploration to determine whether these were 50/50 or dominant two-parent firms. Table 3 shows that there is a difference in $50 / 50 v s$ dominant two-parent firms in terms of knowledge acquisition, so further exploration of 
Table 5 Comparison of high vs low knowledge-acquirer joint ventures

\begin{tabular}{|c|c|c|c|}
\hline Descriptor & $\begin{array}{l}\text { Means: low knowledge acquirers } \\
\qquad(n=84)\end{array}$ & $\begin{array}{l}\text { Means: high knowledge acquirers } \\
\qquad(n=62)\end{array}$ & $\begin{array}{l}\text { Significance } \\
\text { level }\end{array}$ \\
\hline Average Age of JV & 4.95 & 4.72 & n.s. \\
\hline Number of partners & 2.85 & 2.83 & n.s. \\
\hline Percentage of Hungarian ownership & 55.43 & 45.18 & 0.01 \\
\hline $\begin{array}{l}\text { Number of Employees from one of foreign } \\
\text { parents }\end{array}$ & 0.11 & 0.34 & 0.001 \\
\hline Percentage of domestic market sales & 67.22 & 60.27 & n.s. \\
\hline Total years of work experience of president & 21.65 & 22.27 & n.s. \\
\hline Business performance & 3.05 & 3.38 & 0.05 \\
\hline General performance & 3.47 & 3.59 & n.s. \\
\hline Competence \& human resource performance & 2.97 & 3.43 & 0.001 \\
\hline Parent conflict & 2.02 & 2.08 & n.s. \\
\hline Cultural conflict & 1.69 & 1.79 & n.s. \\
\hline Capacity to learn & 4.05 & 4.45 & 0.001 \\
\hline Articulated goals & 0.95 & 1.31 & 0.01 \\
\hline Managerial contribution & 2.72 & 3.24 & 0.001 \\
\hline Technical contribution & 2.76 & 3.38 & 0.001 \\
\hline Foreign parent training & 1.54 & 2.93 & 0.001 \\
\hline
\end{tabular}

two-parent IJVs might help to explain the differences in knowledge acquisition for High vs Low Knowledge-Acquirers.

There were no significant differences between the groups in terms of types of ownership structure, but the results do indicate that in $61 \%$ of the Low Knowledge-Acquirers, the largest partner was Hungarian. Only in $37 \%$ of the High KnowledgeAcquirers was the Hungarian parent the largest equity holder. This suggests the possibility that the relative power of the local parents might affect the propensity of the IJV to draw on information and knowledge of the foreign parent - an unexpected finding. The surface, this seems to suggest that local parent power might be an important omitted variable that should be explicitly examined in further research.

\section{Discussion}

\section{Findings}

\section{IJV characteristics}

The results indicate that capacity to learn, mainly the flexibility, creativity, and knowledge about employees, is a significant indicator of knowledge acquisition from the foreign parent. This is consistent with the work of Cohen and Levinthal (1990), who suggested that knowledge acquisition depended on interactions of organizational members that encouraged creativity. Articulated goals and involvement of the foreign parent in terms of an explicit division of contributions were consistently important as indicators of knowledge acquisition. Moreover, there was also support for the hypothesis that training programs are an important knowledge acquisition mechanism. These help to define a set of knowledge requirements and provide the mechanisms to increase the likelihood of knowledge transfer.

Our results challenge the view that the transfer of technical know-how is the major determinant of knowledge acquisition from the foreign parent, which runs counter to traditional wisdom that technical knowledge is the major resource sought from and/or provided by foreign parents in Hungarian IJVs (Webster, 1992). Our results suggest that tacit, managerial knowledge acquisition has a greater positive impact on the assessments of IJV performance than technical knowledge acquisition. In the Higher Knowledge-Acquisition IJVs, both managerial and technical know-how were significant. For Hungarian managers, this result may indicate that there is a higher premium placed on managerial expertise than on technical expertise. Moreover, placing emphasis on competency-based, managerial know-how may facilitate other exchanges of knowledge. It may also indicate the importance of the social aspects and the human side of knowledge acquisition in which human resource management plays an important role. There is some support for the idea that expatriates 
are an effective vehicle for knowledge acquisition and, in turn, a mechanism for enhancing performance. This finding is interesting given that many theorists (e.g., Bivens and Lovell, 1966; and Killing, 1983) suggested that using expatriates can greatly complicate IJV management.

\section{Ownership and conflict}

Our results indicated that differences in the IJV ownership structure affect at least some aspects of knowledge acquisition. The two-parent shared management joint ventures showed the highest levels of knowledge acquisition from the foreign parents. The results also identify that a lack of knowledge acquisition transfer may result when the domestic parent has the dominant equity position. Both cultural misunderstandings and written goals, in their impact on knowledge acquisition, were moderated by the ownership structure. Specifically, our results suggest that knowledge acquisition in shared management IJVs is affected more directly by cultural misunderstanding, and by having written goals, than is the case for other ownership types. Qualitative studies of IJVs, such as Killing (1983) and Salk (1992), suggested that managing differences and cultural conflicts could be particularly difficult in shared management IJVs. Not having a dominant parent may entail more interaction among the parents and the IJV, caused by a greater need for discussion and negotiation on decisions. While we might expect knowledge acquisition to be greater in a shared management IJV because of frequent interaction and communication (Brown and Duguid, 1991; Westney, 1988), at the same time knowledge acquisition in a shared management IJV may decrease rapidly if there are conflicts and misunderstandings. Thus, a positive knowledge acquisition-shared managerial control relationship may not directly hold. Certainly, a topic of importance for future research is to determine if different ownership and control structures show different propensities for knowledge acquisition and under what conditions.

\section{Knowledge acquisition and performance}

Our results suggested a positive relationship between knowledge acquisition and each of the performance measures. Our results were consistent with the prediction that knowledge acquisition from the foreign parent is significantly related to performance. Further support was shown by the significantly higher performance of the High Knowledge-Acquirers vs Low Knowledge-Acquirers.
However, the significantly higher levels of variance explained by the full regression models (Model 2) in Table 4 suggest that a resource-based view of performance may be a particularly appropriate and productive approach for studying IJVs. More specifically, our findings were consistent with a view in which IJV characteristics and knowledge acquisition-related mechanisms make a general contribution to IJV performance by facilitating adaptation and competence building through knowledge acquisition from multiple sources - not just though knowledge acquisition from the foreign parents. Thus, the scope of future empirical research should be widened to look at multiple sources and targets for knowledge acquisition, including the contributions of the local parents, competitors and industry environments more generally. One implication of our results is that IJV researchers need to develop a greater understanding of what facilitates knowledge acquisition and skill development in IJVs more generally. Our findings suggest that how relationships are structured across organizational stakeholders (e.g., the division of labor, control, responsibility for providing particular inputs in the relationship) and the intra-organizational factors contributing to the knowledge acquisition and knowledge transfer capabilities of an organization, operate as distinct influences on what and how much is learned by an IJV organization.

\section{Organizational knowledge acquisition}

Our findings provide a beginning point for assessing the knowledge acquisition in IJVs from their parent firms. The results lead us to support the theoretical work that addressed organizational knowledge acquisition in IJVs (Lyles, 1988; Hamel, 1991; Kogut and Zander, 1992). We find that absorptive capacity (e.g., flexible IJV structures), shared ownership, conflict, and active involvement of the foreign parent in the IJV influence the degree of knowledge acquisition reported by the joint venture manager in the expected direction. To our knowledge, we are the first to establish empirically that the absorptive capacity of IJV organizations (Cohen and Levinthal, 1990) has a strong relationship with both the ability to assimilate and apply new knowledge.

We also looked at different agendas for knowledge transfer (managerial vs technological contribution) and their relationships with competency-related performance. The importance of explicit and tacit knowledge acquisition are addressed through the agendas for knowledge transfer (managerial vs 
technological contributions) and the importance of the competency-based (human resource) performance. Given the processes that past theory suggests should underlie the mechanisms and characteristics we examined, our findings show that tacit knowledge acquisition cannot be divided on a simple technology $v s$ management basis, and that tacit knowledge seems to be as important as explicit knowledge - if not more important - in predicting partner satisfaction and other performance indicators examined here.

Our results seem to contradict studies suggesting that conflict will always negatively affect knowledge acquisition. It appears that this is true only under certain conditions. Thus, parental conflicts and culture-related conflicts appear to influence organizational knowledge acquisition most strongly in combination with the type of ownership structure. Furthermore, Fiol and Lyles (1985) suggested that there may be certain thresholds when conflict may enhance knowledge acquisition. This is an area that deserves further research attention.

\section{Limitations}

Several limitations of the present study are important. First, the sample is biased toward young IJVs, since their average age is less than five years. This is not surprising, given that the environment of Hungary and the transitional nature of the economy has made foreign investment a relatively recent phenomenon. However, this might limit generalizability of our findings to IJVs in general. The Hungarian context during the late 1980s and early 1990s may cause Hungarian parent organizations to emphasize the positive importance of foreign parent knowledge and competencies more than in a context in which local managers have historical confidence in their administrative and managerial heritages. There could be lagged effects of some organizational variables on knowledge acquisition, as well as a lag between accumulation of knowledge acquisition from the foreign parent and its reflection in terms of performance improvements. We have no data on joint ventures that failed, or that were performing very poorly, so we were not able to determine if lack of knowledge acquisition is related to failure. Another limitation is the focus on structural mechanisms and static characteristics of IJV organizations. Ultimately, a more complete understanding of knowledge acquisition processes in IJVs will necessitate the examination of process over time. Thus, future research should combine the use of questionnaire methods with other measures of knowledge acquisition.

\section{Future Research}

Our findings suggest several avenues for future research. Research assessing partner nationality pairings as an influence on knowledge acquisition and performance might further enhance our understanding of IJVs. For example, Child and Markoczy (1993) already have suggested that certain nationalities or mixes of parent firm nationalities may allow for greater or lesser knowledge acquisition in IJVs. A better understanding of the competencies for knowledge acquisition transfer are also needed. Assessing the management of IJVs for similarities and depth of understanding for the development of new knowledge may provide a knowledge base that facilitates new knowledge transfer (Cohen and Levinthal, 1990). Finally, a more refined understanding of knowledge acquisition and performance could be achieved by using path analysis techniques to assess vertical and horizontal knowledge acquisition in the IJV. This study attempted to assess the knowledge acquisition from the foreign parent. Future studies should assess the knowledge acquisition by all stakeholders, and its impact on the IJV.

\section{Conclusions}

This research was initiated based on two premises. The first was that knowledge acquisition from foreign parents takes place in IJVs. The second was that mechanisms shaping the involvement of the foreign parent, directing and shaping the focus on certain types of information and potential knowledge, as well as organizational characteristics, would all significantly affect knowledge acquisition and IJV performance. Our results were largely consistent with these premises. The results indicate that knowledge acquisition, particularly in shared management IJVs, is related to cultural conflict and to articulated goals. Looking at technology transfers and explicit knowledge acquisition alone greatly underestimates the knowledge acquisition taking place in IJVs.

The managerial implications of our results are that organizational knowledge acquisition in IJVs has an important and positive relationship with IJV performance, particularly in building the competencies of local employees, but also in terms of business performance and global satisfaction of parents in IJVs. Furthermore, the study indicates that explicitly framing foreign parents' 
involvement and support in IJVs has a positive association with the amount of knowledge acquisition reported. The study also indicates that the foreign parents' willingness to be involved, and to provide support in the joint venture, both have an impact on the knowledge acquisition that takes place. It appears that cross-cultural conflict in shared management joint ventures sometimes has a negative impact on knowledge acquisition, and that articulated goals are important to know- ledge acquisition in shared management joint ventures.

\section{Acknowledgements}

We would like to thank the Hungarian-American Blue Ribbon Commission, USAID, Kopint-Datorg, and Duke University's Fuqua School of Business for their research support. We would also like to express our appreciation to Anne Brumbaugh for her work as a research assistant.

\section{References}

Baron, R.M. and Kenny, D.A. (1986) 'The moderator-mediator variable distinction in social psychological research: conceptual, strategic, and statistical considerations', Journal of Personality and Social Psychology 51(6): 1173-1182.

Bivens, K.K. and Lovell, E.B. (1966) Joint Ventures with Foreign Partners, The Conference Board: New York.

Brown, J.S. and Duguid, P. (1991) 'Organizational learning and communities-of-practice', Organization Science 2(1): $40-57$.

Child, J. and Markoczy, L. (1993) 'Host country managerial behavior and learning in Chinese and Hungarian joint ventures', Journal of Management Studies 30(4): 611-631.

Cohen, W. and Levinthal, D. (1990) 'Absorptive capacity: A new perspective on learning and innovation', Administrative Science Quarterly 35: 128-152.

Dess, G.G. and Robinson Jr., R.B. (1984) 'Measuring organizational performance in the absence of objective measures: the case of the privately held firm and conglomerate business unit', Strategic Management Journal 5(3): 265-273.

Dodgson, M. (1993) 'Organizational Learning: a review of some literatures', Organization Studies 14(3): 375-394.

Fiol, M. and Lyles, M. (1985) 'Organizational learning', Academy of Management Review 10: 803-813.

Geringer, J.M. and Hebert, L. (1989) 'Control and performance of international joint ventures', Journal of International Business Studies 20(2): 235-254.

Geringer, J.M. and Hebert, L. (1991) 'Measuring performance of international joint ventures', Journal of International Business Studies 22(2): 249-263.

Hamar, J. (1993) Foreign Direct Investment and Joint Ventures in Hungary: Comparative Study on the Performance of Joint Ventures and National Companies in 1989-1991, KopintDatorg: Budapest, Hungary.

Hamel, G. (1991) 'Competition for competence and interpartner learning within international strategic alliances', Strategic Management Journal 12: 83-103.

Hamel, G., Doz, Y. and Prahalad, C.K. (1989) 'Collaborate with your competitors, and win', Harvard Business Review 67: 133-139.

Hansen, G.S. and Wernerfelt, B. (1989) 'Determinants of firm performance in relative importance of economic and organizational factors', Strategic Management Journal 10(5): 399-411.

Harrigan, K.R. (1986) Managing for Joint Venture Success, Lexington Books: Lexington, MA.

Hedlund, G. (1994) 'A model of knowledge management and the N-Form corporation', Strategic Management Journal 15(Special Issue): 73-90.

Hill, R.C. and Hellriegel, D. (1994) 'Critical contingencies in joint venture management: some lessons from managers', Organization Science 5(4): 594-607.
Hisrich, R.D. and Szirmai, P. (1993) 'Developing a marketoriented economy: a Hungarian perspective', Entrepreneurship and Regional Development 5: 61-71.

Huber, G.P. (1991) 'Organizational learning: the contributing processes and the literatures', Organization Science 2(1): 88-115.

Killing, J.P. (1983) Strategies for Joint Venture Success, Praeger: New York.

Kogut, B. (1988) 'Joint ventures: theoretical and empirical perspectives', Strategic Management Journal 9: 319-332.

Kogut, B. and Zander, U. (1992) 'Knowledge of the firm, combinative capabilities and the replication of technology', Organization Science 3(3): 383-397.

Lane, H.W. and Beamish, P.W. (1990) 'Cross-cultural cooperative behavior in joint ventures in LDCs', Management International Review 30: 87-102.

Lyles, M.A. (1988) 'Learning among joint venture sophisticated firms', Management International Review 28: 85-98.

Lyles, M.A. (1994) 'The impact of organizational learning on joint venture formations', International Business Review 3(4): 459-467.

Lyles, M.A. and Baird, I.S. (1994) 'Performance of international joint ventures in two Eastern European countries: the case of Hungary and Poland', Management International Review 34(4): 313-330.

Lyles, M.A. and Schwenk, C.R. (1992) 'Top management, strategy and organizational knowledge structures', Journal of Management Studies 29(2): 155-174.

March, J.G. (1991) 'Exploration and exploitation in organizational learning', Organization Science 2(1): 71-87.

Markoczy, L. (1993) 'Managerial and organizational learning in Hungarian-Western mixed management organizations', International Journal of Human Resource Management 4(2): 277-304.

Nonaka, I. (1994) 'A dynamic theory of organizational knowledge creation', Organization Science 5(1): 14-37.

Nonaka, I. and Takeuchi, H. (1995) The Knowledge-Creating Company: How Japanese Companies Foster Creativity and Innovation for Competitive Advantage, Oxford University Press: New York.

Nunnally, J. (1967) Psychometric Theory, McGraw-Hill: New York.

Parkhe, A. (1993) 'Partner nationality and the structureperformance relationships in strategic alliances', Organization Science 4: 301-314.

Pedhazur, E.J. (1982) Multiple Regression in Behavioral Research, 2nd edn, Holt, Rinehart and Winston: New York.

Porter, M.E. (1986) 'Competition in global industries: a conceptual framework', in M .E. Porter (ed.) Competition in Global Industries, Harvard Business School Press: Boston, pp: 15-60. 
Prahalad, C.K. and Bettis, R.A. (1986) 'The dominant logic: a new linkage between diversity and performance', Strategic Management Journal 7(6): 485-501.

Salk, J.E. (1992) 'Shared Management Joint Ventures: Their developmental patterns, challenges and possibilities'. Unpublished Ph.D. Dissertation, Sloan School of Management, Massachusetts Institute of Technology, Cambridge, MA.

Salk, J.E. (1996) 'Partners and other strangers: cultural boundaries and cross-cultural encounters in international joint venture teams', International Studies of Management and Organization 26(4): 48-72.

Szulanski, G. (1993) 'Intra-firm transfer of best practice, appropriative capabilities, and organizational barriers to appropriation', in D.P. Moore (ed.), Academy of Management Best Papers Proceedings 1993, 53rd Annual Meeting, Atlanta GA, August 8-11, pp: 47-51.

von Hippel, E. (1988) The Sources of Innovation, MIT Press: Cambridge, MA.

von Krogh, G., Roos, J. and Slocum, K. (1994) 'An essay on corporate epistemology', Strategic Management Journal 15(Special Issue): 53-71.

Webster, L. (1992) 'Private sector manufacturing in Hungary: a survey of firms'. Industry Development Division, Industry and Energy Department, World Bank.

Westney, D.E. (1988) 'Domestic and foreign learning curves in managing international cooperative strategies', in F.J. Contractor and $\mathrm{P}$. Lorange (eds.) Cooperative strategies in international business, Lexington: Lexington, MA., pp: 339-346.

Yan, A. and Gray, B. (1994) 'Bargaining power, management control and performance in United States-China joint ventures: a comparative case study', Academy of Management Journal 37(6): 1478-1517.

\section{Appendix: Definition of variables}

AGE: Control variable calculated as 1994 minus JV founding date.

SIZE: Control variable, reported initial capitalization in forints.

KNOWL: Seven-item scale summarizing Likert-type responses to the question, To what extent have you learned from your foreign parent (a) new technological expertise, (b) new marketing expertise, (c) product development, (d) knowledge about foreign cultures and tastes, (e) managerial techniques, and (f) manufacturing processes (where $1=$ little; $5=$ to a great extent; alpha $=0.88$ ).

CAPACITY: Three-item scale of Likert-type items based on the extent to which the IJV is flexible and adapting to change, creative and superiors know about employee performance (where $1=$ strongly disagree and $5=$ strongly agree; alpha $=0.71$ ).

GOALS: Indicates whether the IJV has written objectives and/or a written long-term plan (where $0=$ neither are written, $1=$ either are written and $2=$ both are written).

MGRCNTRIBUTE: Six-item scale that summarizes the degree to which the foreign parent(s) contri- butes to the IJV in the following areas: sales/marketing support, managerial resources, administrative support, emotional support, training, and time (where $1=$ less than expected and $5=$ more than expected; alpha $=0.84$ ).

TECHCNTRIBUTE: Three-item scale that summarizes the degree to which the foreign parent(s) contributes to the IJV in the following areas: product related technology, manufacturing-related technology, and manufacturing support (where $1=$ less than expected and $5=$ more than expected; alpha=0.86).

CONTRIBUTE: Extent to which the foreign parent provides the technology while the domestic parent provides the manufacturing capability (where $1=$ strongly disagree and $5=$ strongly agree).

TRAINING: The extent to which the foreign parent provides education and training of domestic managers (where $1=$ strongly disagree and $5=$ strongly agree).

CULTURE: Two-item scale that summarizes the extent to which cultural misunderstandings and cultural differences have been issues in the IJV (where $1=$ little and $5=$ very much; alpha $=0.87$ ).

PARCONFLICT: Three-item scale that summarizes the extent to which mistrust, conflict over the original IJV agreement, and cultural differences between the parents have been issues in the IJV (where $1=$ little and $5=$ very much; alpha $=0.79$ ).

OWN (D1): Dummy variable set up where $1=$ shared management (two partners and 50/50 equity); $0=$ others.

OWN (D2): Dummy variable where $1=$ dominant parent with majority equity position in two-parent IJV; $0=$ others.

BUSPERF: Four-item Likert-type scale that summarizes the IJV's performance in the following areas: increasing business volume, increasing market share, achieving planned goals, and making profits (where $1=$ poor to $5=$ excellent; alpha $=0.82$ ).

HRPERF: Two-item Likert-type scale that summarizes human resource (competency-based) performance in providing adequate worker training and improving management skills (alpha=0.66).

GENPERF: Three-item Likert-type scale that summarizes how the Hungarian parent, the foreign parent, and the respondent evaluate the IJV's performance (alpha $=0.88$ ).

This paper was previously published in Journal of International Business studies (1996) 27, 877-903. 